\title{
Impactos do ácaro da necrose no desenvolvimento de frutos híbridos de coqueiros em
}

\section{plantio comercial}

\author{
Impacts of necrosis mite on the development of hybrid coconut fruits in commercial planting \\ Impactos del ácaro de la necrosis en el desarrollo de frutos de coco híbridos en plantaciones \\ comerciales
}

Recebido: 02/12/2021 | Revisado: 13/12/2021 | Aceito: 13/12/2021 | Publicado: 20/12/2021

\author{
Natanael Charles da Silva \\ ORCID: https://orcid.org/0000-0001-5261-3691 \\ Instituto Federal de Educação, Ciência e Tecnologia do Pará, Brasil \\ E-mail: natanaelcharles@gmail.com \\ Melbya Moraes Rolim \\ ORCID: https://orcid.org/0000-0002-3694-9053 \\ Instituto Federal de Educação, Ciência e Tecnologia do Pará, Brasil \\ E-mail: melbymr36@gmail.com
}

\begin{abstract}
Resumo
O trabalho objetivou analisar os principais impactos causados pelo ácaro da necrose em cocos híbridos em um plantio comercial de coco, além de verificar qual híbrido é o mais resistente aos danos causados pela praga. Para isso, as coletas foram realizadas em um plantio comercial em parcelas subdivididas no espaço e no tempo. Durante a pesquisa, foram analisados no software Assistat o peso do albúmen sólido, o volume de albúmen líquido e a severidade de dano na fibra de 1920 cocos divididos em três níveis de danos. Os resultados evidenciaram que o coco híbrido de identificação PB-123 demonstrou maior peso de albúmen sólido, maior volume de albúmen líquido e menor severidade de dano na fibra, logo, esse híbrido foi identificado como o mais resistente aos ataques dessa praga. Levando em consideração a chuva como fator limitante à praga, notou-se que os cocos coletados se desenvolveram significativamente melhor nos períodos de crescimento inicial com maiores índices pluviométricos. Com esses dados, é possível atribuir atenção especial ao híbrido PB-123 em próximas plantações, caracterizando-o como o híbrido mais resistente aos danos provocados pelo ácaro. Reafirma-se que o ácaro causador da necrose é de fácil dispersão e causa danos profundos no fruto do coqueiro, podendo estar associado a perdas de valor comercial para seus produtores.
\end{abstract}

Palavras-chave: Cocoicultura; Praga do coqueiro; Híbrido; Resistência.

\begin{abstract}
The study aimed to analyze the main impacts caused by the necrosis mite on hybrid coconuts in a commercial coconut plantation, in addition to verifying which hybrid is the most resistant to damage caused by the pest. For this purpose, the collections were carried out in a commercial plantation in plots sub-divided in space and time. During the research, the weight of the solid albumen, the volume of liquid albumen and the damage severity in the fiber of 1920 coconuts were analyzed in the Assistant software, divided into three levels of damage. The results showed that the hybrid coconut identified by PB-123 showed greater weight of solid albumen, greater volume of liquid albumen and less severity of damage to the fiber, therefore, this hybrid was identified as the most resistant to attacks by this pest. Taking into account the rain as a limiting factor for the pest, it was noted that the collected coconuts developed significantly better in the periods of initial growth with higher rainfall. With these data, it is possible to give special attention to the PB-123 hybrid in future plantations, characterizing it as the most resistant hybrid to damage caused by the mite. In addition to reaffirming that the mite that causes necrosis is easy to disperse and causes profound damage to coconut fruit, which may be associated with loss of commercial value for its producers.
\end{abstract}

Keywords: Cocoiculture; Coconut pest; Hybrid; Resistance.

\section{Resumen}

El estudio tuvo como objetivo analizar los principales impactos provocados por el ácaro de la necrosis en cocos híbridos en una plantación comercial de cocoteros, además de verificar qué híbrido es el más resistente al daño causado por la plaga. Para ello, las recolecciones se realizaron en una plantación comercial en parcelas subdivididas en espacio y tiempo. Durante la investigación, se analizaron en el software Assistat el peso de la albúmina sólida, el volumen de la albúmina líquida y la 
severidad del daño en la fibra de 1920 cocos, divididos en tres niveles de daño. Los resultados mostraron que el coco híbrido identificado por PB-123 presentó mayor peso de albúmina sólida, mayor volumen de albúmina líquida y menor severidad de daño a la fibra, por lo que este híbrido fue identificado como el más resistente a los ataques de esta plaga. Teniendo en cuenta la lluvia como factor limitante de la plaga, se observó que los cocos recolectados se desarrollaron significativamente mejor en los períodos de crecimiento inicial con mayor precipitación. Con estos datos, es posible dar especial atención al híbrido PB123 en futuras plantaciones, caracterizándolo como el híbrido más resistente a los daños ocasionados por el ácaro. Además de reafirmar que el ácaro que causa necrosis es fácil de dispersar y causa daños profundos al fruto del coco, lo que puede estar asociado con una pérdida de valor comercial para sus productores.

Palabras clave: Cocoicultura; Plaga de coco; Híbrido; Resistencia.

\section{Introdução}

No Brasil, os maiores cultivadores de coco estão localizados nas regiões Norte e Nordeste, com destaque para o estado do Pará, sendo favorecido pelo clima quente e úmido (Brasil, 2018). Dessa maneira, a cocoicultura no Brasil vem-se destacando nos últimos anos, principalmente por intermédio de incentivos à produção de coco seco, in natura, coco ralado, leite de coco, óleo de coco e água de coco (IBGE, 2017).

A cocoicultura tem grande importância socioeconômica, principalmente para as regiões Norte e Nordeste do país, gerando emprego e renda para habitantes dessas regiões. Trata-se de uma cultura que permite consórcio com outras culturas e até mesmo a criação de animais, contribuindo para o desenvolvimento do homem do campo (Rodrigues et al., 2016).

O coqueiro (Cocos nucifera) é popularmente compreendido como a “Árvore do Bem-Estar", o que, de fato, se confirma, pois produz um dos frutos tropicais mais nutritivos cultivados em território nacional. Ele é um composto natural de proteínas, calorias, carboidratos, gorduras, vitaminas A e B e sais minerais, como potássio e magnésio, isso o torna um fruto que apresenta $100 \%$ de aproveitamento (Brasil, 2018).

Quando o objetivo é a industrialização do consumo in natura do coco, Alves \& Müller (1995) afirmam que o fruto deve ser colhido entre 11 e 12 meses de idade, necessitando de bastante água e nutrientes para que tenha uma boa formação. No entanto, segundo Lins (2009) doenças foliares, como o anel vermelho, a murcha-de-phytomonas, as brocas do olho-do-coqueiro e da coroafoliar, o ácaro-da-necrose-do-fruto e os insetos desfolhadores e sugadores de modo geral, são algumas das enfermidades fitossanitárias de destaque na cultura do coqueiro, podendo, segundo Juhász et al. (2013), comprometer a produtividade em todas as fases de desenvolvimento, bem como, a qualidade final do produto.

No Brasil já foram registradas quatro espécies diferentes de ácaros parasitas em coqueiros, os quais são: Aceria (Eriophyes) guerreronis (Keifer, 1965); Tetranychus mexicanus (McGregor 1950); Amrineus cocofolius (Flechtmann, 1994); e Retracrus johnstoni (Keife, 1965). Entre esses, o Aceria guerreronis é classificado como uma praga severa, que atinge quase todas as regiões em que a cocoicultura é de grande relevância (Ferreira et al., 1998).

Também conhecido como Ácaro-da-necrose-do-coqueiro, o A. guerreronis, pertence à família Eriophyidae, sua estrutura é alongada, vermiforme e de pequeno porte (Flechmann, 1979), apresenta cor branco-leitosa ou, em alguns casos, levemente amarelado e brilhante. É um organismo típico dos eriofídeos, pois apresenta dois pares de patas na parcela anterior e um orifício anal na extremidade posterior. Seu ciclo varia entre 8 e 11 dias de vida, o que caracteriza essa praga como de grande potencial reprodutivo (Suarez \& Almaguel, 1992).

Essa espécie de ácaro tem preferência por atacar cocos nos estágios iniciais de desenvolvimento, visto que o espaço entre a bráctea e o fruto são maiores em relação aos cocos mais desenvolvidos. Com isso, ele se instala nesse local e se alimenta, processo que resulta na necrose marrom escuro que inicia na parte inferior das brácteas e se estende para o corpo do fruto (Alencar et al., 1999). 
Diante disso, a presente pesquisa objetivou analisar os principais impactos causados pelo ácaro da necrose em cocos híbridos em um plantio comercial de coco, além de verificar qual híbrido é o mais resistente aos danos causados pela praga.

\section{Material e Métodos}

\section{Delimitação da área de estudo}

A pesquisa é classificada como um estudo de campo, que segundo Raupp \& Beuren (2006) é caracterizado pelo estudo profundo e exaustivo de um ou de poucos objetos, de maneira a permitir conhecimentos amplos e detalhados do mesmo. As coletas foram realizadas em um plantio comercial localizado no município de Mojú, na região nordeste do estado do Pará, que pertence à parte oriental da Amazônia, Brasil, apresentando coordenadas: 01 53' 10" de latitude Sul, 48 46' 00'” de longitude a Oeste do meridiano de Greenwich (Figura 1) e estando a uma altitude de 16 metros do nível do mar.

Figura 1. Localização da área de plantio comercial no município de Mojú-PA, na Amazônia oriental, onde foram realizadas as coletas.

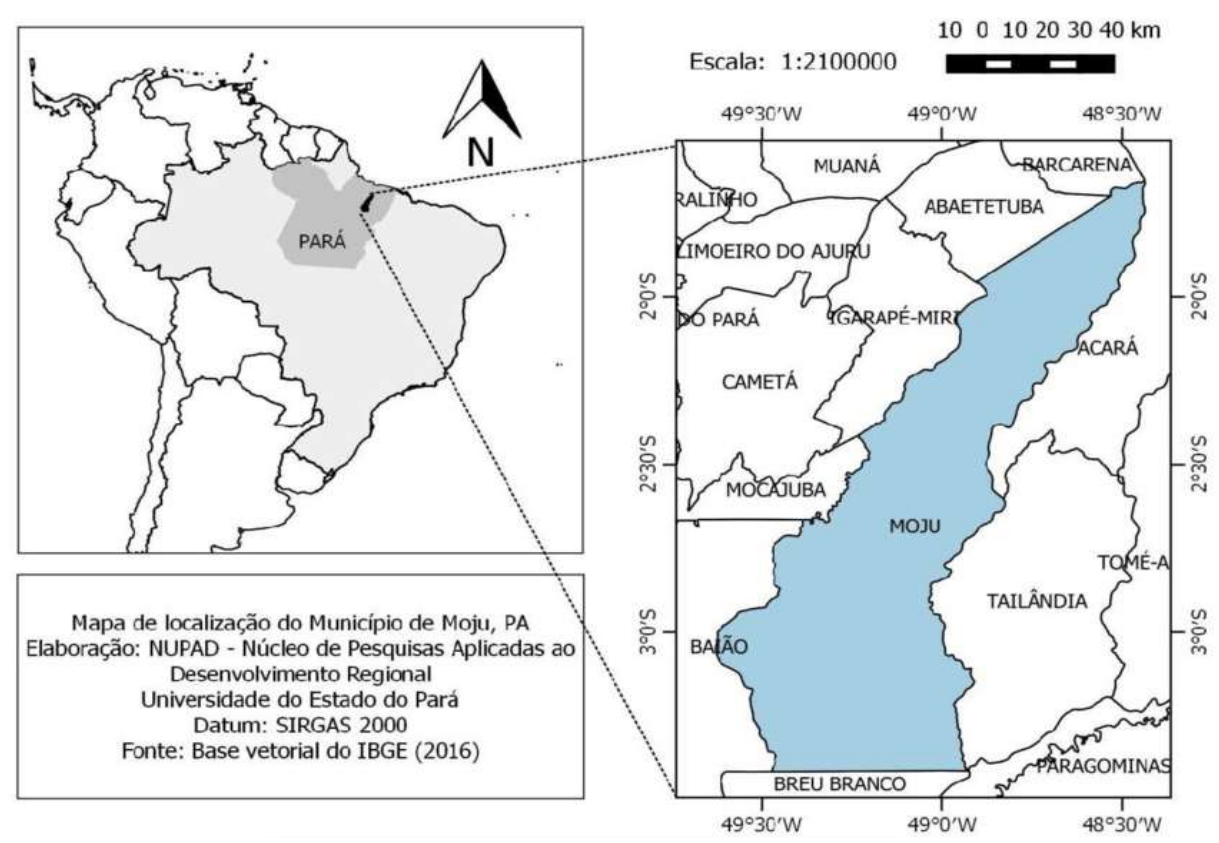

Fonte: IBGE (2020).

A área total do plantio é de aproximadamente 20.000 hectares (Figura 2), toda dividida em parcelas, com dimensão de $250.000 \mathrm{~m}^{2}$, possuindo 136 linhas plantadas. Em condições normais, acumula 4080 coqueiros plantados. 
Figura 2. Estrada que divide o plantio comercial em parcelas.

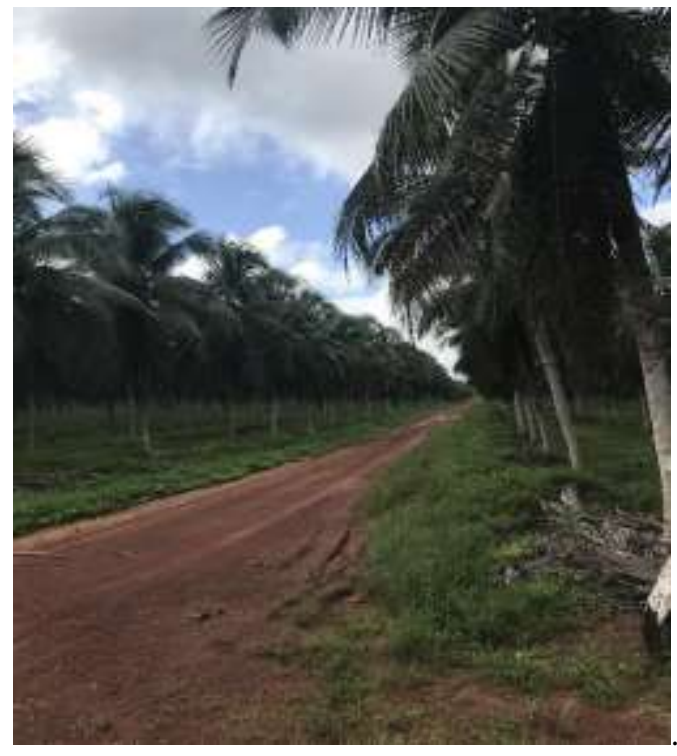

Fonte: Arquivo pessoal (2019).

As parcelas onde foram realizadas as coletas se encontravam em condições normais de produção, possuíam um ciclo de colheita dos frutos de 45 dias e de adubação de uma vez ao ano, sendo selecionadas quatro parcelas diferentes para o estudo.

\section{Coleta das amostras}

Foram realizadas 4 coletas, sendo as duas primeiras durante o verão, e as duas últimas no inverno. As duas primeiras coletas foram realizadas, respectivamente, nos meses de agosto e novembro do ano de 2018, já as duas últimas foram realizadas, respectivamente, em fevereiro e abril de 2019.

Os cocos colhidos foram selecionados por numeração de cachos. Esse registro se dá de acordo com o número da folha à qual o cacho pertence, partindo-se do princípio de que um coqueiro que está sujeito a condições ambientais favoráveis ao seu desenvolvimento apresenta cerca de 25 a 30 folhas em sua copa. A contagem inicia-se a partir das folhas mais jovens para as mais velhas.

Em cima de cada folha, há o desenvolvimento de uma inflorescência que, posteriormente, dará origem a um cacho. Sendo assim, os cocos colhidos apresentam diferentes períodos de colheita, de acordo com seu desenvolvimento e destino dentro do plantio comercial.

Os cocos que foram coletados para a análise na presente pesquisa pertencem ao cacho da folha 28 (ficam no coqueiro durante um período de 11 a 12 meses até serem colhidos), exatamente porque são cocos destinados, principalmente, à produção de coco ralado. No entanto, o albúmen líquido desses cocos também é aproveitado, para isso é necessário que o coco apresente grande volume de albúmen sólido, necessitando ser colhido tardiamente em relação a outros cachos.

Para os cocos coletados no mês de agosto de 2018, verificou-se que a pluviosidade variou de 30 a $70 \mathrm{~mm}$ ao mês, já para os coletados no mês de novembro de 2018, esse índice variou de 10 a 220 mm ao mês. Para os cocos coletados no mês de fevereiro de 2019, verificou-se que o índice pluviométrico no período a ser considerado variou de 350 a $420 \mathrm{~mm}$ ao mês, mesmo índice da variação encontrado para os cocos que foram coletados no mês de abril de 2019. 
Os frutos dos quatro híbridos de coqueiro analisados foram identificados como: PB-132, PB-121, PB-141 e o PB-123, modalidade de identificação padrão entre os plantios comerciais de cocos. Esses híbridos são originados a partir dos cruzamentos das variedades de coqueiro anão (verde, amarelo e vermelho) e coqueiro gigante.

Durante cada período de coleta, foram selecionados quatro big bags (grandes sacos usados para estocar coco), repletos de cocos de cada parcela, em seguida, os cocos foram retirados e classificados visualmente em três níveis diferentes de danos causados pelo A. guerreronis (Tabela 1).

Tabela 1 - Os três níveis de danos nos cocos provocados pelo A. guerreronis nos cocos dos que pertencem ao cacho da folha 28.

\begin{tabular}{c|l}
\hline Nível & \multicolumn{1}{|c}{ Características } \\
\hline $\mathbf{1}$ & $\begin{array}{l}\text { Cocos com sintomas iniciais de necrose que aparentemente não afeta o } \\
\text { desenvolvimento, ou seja, sem perda no valor do fruto. }\end{array}$ \\
\hline $\mathbf{2}$ & $\begin{array}{l}\text { Cocos com área necrosada de tamanho mediano com poucas deformações e uma leve } \\
\text { diminuição no tamanho do fruto. }\end{array}$ \\
\hline $\mathbf{3}$ & $\begin{array}{l}\text { Cocos que possuem grande parte de sua casca coberta por necrose que gera graves } \\
\text { deformações no fruto e que acaba limitando consideravelmente o seu crescimento. }\end{array}$ \\
\hline
\end{tabular}

Fonte: Adaptado de Julia e Mariau (1979).

Após a divisão dos cocos por nível de dano, foi selecionado um coco como padrão para cada nível (Figura 3).

Figura 3. Cocos selecionados por big bag como padrões de cada nível de dano causado pelo A. guerreronis.

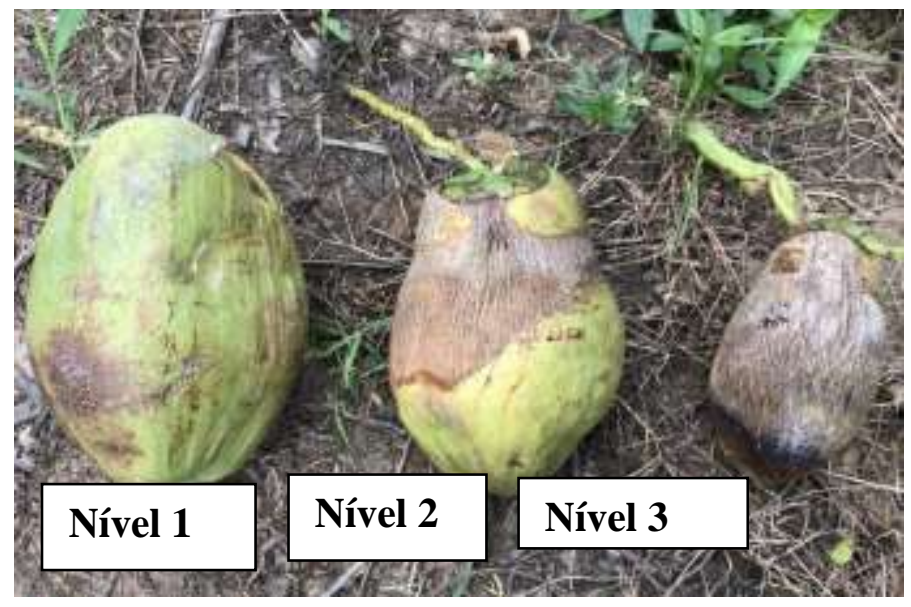

Fonte: Arquivo pessoal (2019).

A partir da seleção desses cocos padrões, foram selecionados dez cocos de cada nível e postos separadamente em sacos de 50 kg, identificados por parcela, híbrido, nível de dano e número do big bag (Figura 4). 
Figura 4. Sacos de $50 \mathrm{~kg}$ onde os cocos foram armazenados para serem levados a laboratório, a fim de serem analisados.

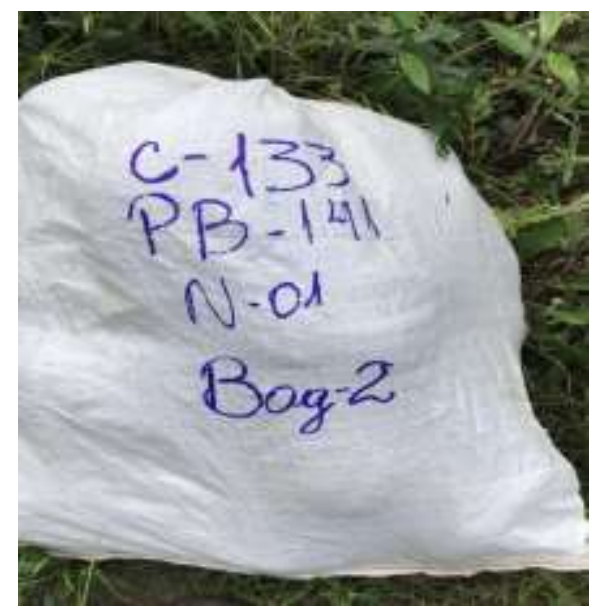

Fonte: Arquivo pessoal (2019).

Dessa forma, foram coletados 120 cocos dos quatro big bags de cada parcela por período de coleta, totalizando assim 480 cocos por período de coleta e 1920 cocos ao final de todas as coletas de todas as parcelas.

A cada período de coleta, foi realizada a pesagem em mg do fruto inteiro, a pesagem da amêndoa, da fibra, do endocarpo, do mesocarpo, do albúmen sólido e do albúmen líquido em ml de cada coco coletado.

\section{Obtenção e análise dos dados}

Os dados da pesagem de cada componente de cada coco coletado foram anotados, inicialmente em tabelas produzidas pelo Excel versão 2013, posteriormente, essas tabelas foram organizadas a cada 40 cocos por período de coleta e por nível de ataque, onde foi calculada a média do albúmen sólido, do albúmen líquido e da fibra separadamente de cada 10 cocos coletados. Isso se fez necessário por ser o número de frutos coletados por nível de cada big bag.

Por conseguinte, os valores obtidos das médias foram inseridos no software Assistat, que é capaz de classificar médias, analisar variância e aplicar testes científicos, realizando também o teste Tukey, podendo constatar com este quais os híbridos mais resistentes ao A. guerreronis em parcelas subdivididas no espaço e no tempo.

\section{Resultados e Discussão}

Foi verificado que, nos cocos coletados no mês de novembro, obteve-se um quantitativo menor de infecção pelo ácaro da necrose, pois, de acordo com Lindquist \& Oldfield (1996), devido à ausência de adaptações morfológicas, como pedicelos ou garras, esse ácaro não consegue fixar-se de forma mais efetiva no fruto, sendo assim, a chuva intensa acaba tirando essa praga do coco.

Quando o índice pluviométrico é alto, principalmente no período inicial de desenvolvimento do coco, o fruto tende a ser mais saudável, visto que é o período mais suscetível aos ataques dessa praga, pois nesse período as brácteas não são fixadas com o mesmo rigor de quando é um coco mais desenvolvido (Alencar et al., 1999). Esta influência pluviométrica é observava também em outras plantações, como no trabalho de Cruz et al. (2021), onde apresenta que o estresse hídrico promoveu reduções significativas no conteúdo relativo de água, área foliar e nas produções de massas secas, em plantas jovens de açaizeiro. 
Com relação à análise do albúmen sólido, o teste Tukey mostra uma diferença mínima significativa de 11.66524 entre a classificação de A e C, onde A é o nível menos impactado e C o nível mais impactado pelo A. guerreronis (Tabela 2).

Tabela 2 - Comparação das médias por nível de ataque nos 4 híbridos.

\begin{tabular}{c|c|c}
\hline Nível & Resultados & Classificação \\
\hline $\mathbf{1}$ & 384.63130 & A \\
\hline $\mathbf{2}$ & 345.90310 & B \\
\hline $\mathbf{3}$ & 265.27970 & $\mathrm{C}$ \\
\hline
\end{tabular}

Fonte: Dados da pesquisa (2019).

Pode-se observar que os valores dos cocos do Nível 1, que não apresentam seu desenvolvimento prejudicado pelo $A$. guerreronis, são bem maiores em relação aos outros dois níveis de dano, principalmente quando comparado ao Nível 3, considerado o mais danificado por essa praga. Com isso, fica evidenciada a perda do valor comercial do fruto devido à diminuição de albúmen sólido como consequência dos impactos provocados pelo A. guerreronis.

$\mathrm{Na}$ comparação das médias do peso em mg do albúmen fresco dos híbridos por níveis de ataque, a diferença mínima significativa foi de 17.57113, indicando que o híbrido mais resistente para o menos resistente está classificado na escala entre A e C (Tabela 3).

Tabela 3 - Comparação das médias por mês avaliado pelo Teste Tukey a 1\%.

\begin{tabular}{c|c|c}
\hline Híbrido & Resultados & Classificação \\
\hline PB-123 & 384.61670 & A \\
\hline PB-132 & 358.83960 & B \\
\hline PB-141 & 295.22290 & C \\
\hline PB-121 & 289.07290 & C \\
\hline
\end{tabular}

Fonte: Dados da pesquisa (2019).

Com relação às médias por mês de coleta, é possível observar, por meio das coletas realizadas, que os meses de fevereiro de 2019 e novembro de 2018 apresentam-se como o primeiro e segundo mês respectivamente que possuem valores danosos menos elevados (Tabela 4).

Tabela 4 - Comparação das médias por mês avaliado pelo Teste Tukey a 1\%.

\begin{tabular}{c|c|c|c}
\hline Ano & Mês & Resultado & Classificação \\
\hline $\mathbf{2 0 1 8}$ & Agosto & 239.64170 & C \\
\hline $\mathbf{2 0 1 8}$ & Novembro & 372.30830 & A \\
\hline $\mathbf{2 0 1 9}$ & Fevereiro & 374.05210 & A \\
\hline $\mathbf{2 0 1 9}$ & Abril & 341.75000 & B \\
\hline
\end{tabular}

Fonte: Dados da pesquisa (2019). 
Esse fato está de acordo com o encontrado na pesquisa de Balaji \& Hemavathi (2007), quando relatam que a densidade populacional de A. guerreronis está relacionada negativamente com a precipitação. Dessa forma, os cocos que pertencem a esses meses de coleta tiveram sua formação há mais ou menos um ano, ou seja, os cocos colhidos em fevereiro de 2019 se formaram entre fevereiro e março de 2018, e os colhidos em novembro de 2018 se formaram entre outubro e dezembro de 2017, apresentando uma boa sequência de altos índices pluviométricos nos meses seguintes, refletindo significativamente no aumento do peso do albúmen e na diminuição das populações do A. guerreronis, o que possibilitou aos cocos se desenvolverem bem mais sadios em relação aos cocos coletados durante o verão.

O segundo componente do coco que teve os valores dos pesos de suas médias analisadas foi o albúmen líquido, apresentando diferença mínima significativa de 12.75539, conforme Tabela 5.

Tabela 5 - Comparação das médias do albúmen líquido por nível de ataque nos 4 híbridos.

\begin{tabular}{c|c|c}
\hline Nível & Resultados & Classificação \\
\hline $\mathbf{1}$ & 255.40160 & $\mathrm{~A}$ \\
\hline $\mathbf{2}$ & 207.16720 & $\mathrm{~B}$ \\
\hline $\mathbf{3}$ & 121.04530 & $\mathrm{C}$ \\
\hline
\end{tabular}

Fonte: Dados da pesquisa (2019).

Os valores dos cocos do Nível 1, que não tiveram seu desenvolvimento prejudicado pela ocorrência do A. guerreronis, são bem maiores quando comparados aos outros dois níveis de dano. Com isso, é possível observar as perdas de albúmen líquido devido a infestação do A. guerreronis. Desta forma, a produtividade é comprometida devido a redução do valor comercial desse fruto mais impactado.

Com base nas médias do volume do albúmen líquido em $\mathrm{ml}$, obteve-se que o híbrido mais resistente aos danos ocasionados pelo A. guerreronis também é o híbrido PB-123, o segundo mais resistente é o PB-132 e, por último, os híbridos PB-141 e o PB121. Autores como Mariau (1977) correlacionam esse fato com a rigidez da bráctea, apontando esta como fator que proporciona menor entrada dessa praga no tecido meristemático, diminuindo assim a vulnerabilidade desse fruto, caracterizando-o como, de certa forma, resistente.

Já com relação à comparação das médias por mês avaliado, registra-se a diferença mínima significativa de 15.51144 (Tabela $6)$.

Tabela 6 - Comparação das médias de albúmen líquido nos 4 meses avaliados.

\begin{tabular}{c|c|c|c}
\hline Ano & Mês & Resultado & Classificação \\
\hline $\mathbf{2 0 1 8}$ & Agosto & 86.35208 & C \\
\hline $\mathbf{2 0 1 8}$ & Novembro & 229.13750 & AB \\
\hline $\mathbf{2 0 1 9}$ & Fevereiro & 244.95210 & A \\
\hline $\mathbf{2 0 1 9}$ & Abril & 217.71040 & B \\
\hline
\end{tabular}

Fonte: Dados da pesquisa (2019). 
Percebe-se que as coletas dos meses de fevereiro de 2019 e novembro de 2018 apresentam-se como o primeiro e segundo mês, respectivamente, que possuem os valores de danos menos elevados, ou seja, foram os meses que tiveram maior volume de albúmen líquido. Da mesma forma, Cavalcante (2019) observou em sua pesquisa que o período de maior precipitação contribuiu para o crescimento dos frutos usados, tal como controlou boa parte das populações de A. guerreronis.

Com relação à análise da fibra do coco, o híbrido PB-121 mostrou-se com severidade de dano de $62 \%$, ou seja, o maior valor entre as médias dos outros híbridos (Tabela 7).

Tabela 7 - Análise das médias de severidade de dano entre os híbridos e os meses avaliados.

\begin{tabular}{c|c|c|c|c|c}
\hline Híbridos & $\begin{array}{c}\text { Agosto } \\
\mathbf{2 0 1 8}\end{array}$ & Novembro 2018 & Fevereiro 2019 & $\begin{array}{c}\text { Abril } \\
\mathbf{2 0 1 9}\end{array}$ & $\begin{array}{c}\text { Média } \\
\text { Geral }\end{array}$ \\
\hline PB-123 & 78 & 65 & 46 & 40 & $\mathbf{5 7}$ \\
\hline PB-132 & 74 & 42 & 45 & 42 & $\mathbf{5 0}$ \\
\hline PB-141 & 66 & 67 & 55 & 49 & $\mathbf{5 9}$ \\
\hline PB-121 & 76 & 69 & 53 & 50 & $\mathbf{6 2}$ \\
\hline
\end{tabular}

Fonte: Dados da pesquisa (2019).

Dessa forma, fica evidente que esse híbrido possui maior sensibilidade aos ataques do ácaro causador da necrose quando comparado aos outros três híbridos analisados. O segundo a demonstrar-se mais impactado foi o híbrido PB-141, que teve severidade de $59 \%$.

Sendo assim, o primeiro e o segundo híbrido que apresentaram menores valores de severidade de dano foram o PB-132 e o PB-123, respectivamente. Esses resultados se diferem dos analisados por Cavalcante (2019), onde o híbrido mais sensível detectado em sua pesquisa foi o PB-132, com $73 \%$ de severidade, seguido do PB-123, com 70\%, fato esse que pode estar relacionado ao período de plantação dos coqueiros.

Com estes dados, é possível que novos plantios levem em consideração as características fisiológicas do coqueiro a ser plantado, bem como, o período em que irá ocorrer a plantação, considerando a elaboração de um plano de manejo, pois muitas características da área são observadas e analisadas, e assim é montado um diagnóstico, propondo medidas de desenvolvimento e conservação conforme a finalidade da plantação (Medeiros et al., 2021).

\section{Conclusões}

Os dados da pesquisa reafirmam que o ácaro causador da necrose (A. guerreronis) apresenta forte impacto no desenvolvimento de frutos de coqueiros híbridos. Entre esses impactos, apontamos: a redução do albume sólido e líquido do fruto, menor peso total do fruto e comprometimento da fibra do coco. Todos esses impactos causam redução da qualidade do fruto produzido e, consequentemente, comprometimento no valor comercial do coco.

$\mathrm{O}$ estudo evidencia ainda a chuva como fator limitante às populações de A. guerreronis, verificando-se que, quando se compara os valores obtidos nos meses mais chuvosos com os mais secos no momento da formação dos cocos, é possível observar que os cocos coletados se desenvolveram significativamente melhor, ou seja, tiveram os maiores pesos de albúmen sólido e líquido e menor índice de severidade da fibra (epicarpo e mesocarpo) nos períodos em que os híbridos tiveram seu crescimento inicial em meses com maiores índices pluviométricos.

Com relação ao comparativo entre os híbridos analisados, o que apresentou menor impacto pelos danos causados pelo $A$. guerreronis foi o PB-123, seguido do PB-132. Tal resistência pode estar diretamente ligada à origem desses dois híbridos, os quais 
possuem como ancestral comum a variedade Gigante do Oeste Africano. No entanto, apontamos essa hipótese como lacuna para futuras pesquisas na área.

Como possíveis soluções para a redução dos impactos causados pelo ácaro da necrose nos frutos dos coqueiros, apontamos o planejamento do plantio dos cocos, adequando o plantio de forma que o desenvolvimento inicial dos cachos ocorra em períodos mais chuvosos na região onde o plantio comercial se encontra. Além disso, estudos sobre a origem genética da espécie a ser planta pode indicar fatores de resistência da própria planta contra a praga, reduzindo os impactos e alcançando um consequente melhor aproveitamento do fruto a ser comercializado.

\section{Agradecimentos}

Agradecemos especialmente a Empresa Sococo S.A situada no município de Moju no estado do Pará, por ter nos recebido e permitido a execução da pesquisa no seu plantio. Ao Instituto Federal do Pará, Campus Abaetetuba, em especial o Laboratório de Biodiversidade e Conservação - LABICON.

\section{Referências}

Alencar, J. Á.; Haji, F. N. P \& Moreira, F. R. B. (1999). Ácaro da Necrose do Coqueiro, Aceria guerreronis (Keifer). Petrolina.

Alves, M. A \& Müller, A. A. (1995). Aspectos Básicos do Cultivo do Coqueiro (Cocos nucifera L.). Belém-PA.

Balaji, k \& Hemavathi, A. T. (2007). Studies on the Seasonal Incidente of Coconut Eriophyid Mite Aceria guerreronis Keifer (Acari: Eriophydae). Asian Journal of Bio Science, 2(1), 88-91.

Brasil, Sococo S.A. (2020). Agroindústria da Amazônia. Webesite Sococo. http://www.sococo.com.br/unidade-moju-pa/.

Cavalcante, I. P. (2019). Resistência e Perdas Econômicas de Híbridos de Coqueiro (Cocus nucifera L.) A Aceria guerreronis Keifer (Acari: Eriophydae) no Município de Moju, Pará. Dissertação (Mestrado em Agronomia: área de concentração Produção Vegetal em Sistemas Agrícolas) -Universidade Federal Rural da Amazônia. Belém, PA.

Cavalcante, L. V. (2015). A nova geografia do coco: Reestruturação produtiva, Territorialização do capital e dinâmicas socioespaciais. 298 f, Dissertação (Mestrado em Geografia) - Universidade estadual do Ceará. Fortaleza-CE.

Cruz, M. S. F. V., Farias, P. M. dos R., Alves, J. D. N., Conceição, H. E. O. da., Sauma Filho, M., Silva, J. V. S. e., Aguiar, A. C. S., Silva, P. M. da, Pinheiro, M. da C., \& Oliveira, J. N. de. (2021). Crescimento e desenvolvimento de plantas jovens de açaizeiro sob déficit hídrico em Latossolo Amarelo. Research, Society and Development, 10(12), e496101220582. https://doi.org/10.33448/rsd-v10i12.20582.

Ferreira, J. M. S.; Warwick, D. R. N \& Siqueira, L. A. (1998). A Cultura do Coqueiro no Brasil. 2. ed. Brasília: Embrapa, 247p.

Flechtmann, C. H. N. (1979). Ácaros de importância agrícola. 3. ed. São Paulo: Nobel, 189p.

Flechtmann, C. H. N. (1994). Amrineus cocofolius n. g., sp. (Acari: Eriophydae) from Brazil. International Journal of Acarology, 20(1), 57-59.

Haq, M. A.; Sumangala, K \& RAMANI, N. (2002). Coconut Mite Invasion, Injury And Distribution, p. 41-49. In L.C.P. Fernando, G. J. MORAES \& I. R. Wickramananda (eds.), Proceedings of the International Workshop on Coconut Mite (Aceria guerreronis). Sri Lanka, Coconut Research Institute, $117 \mathrm{p}$.

IBGE. Instituto Brasileiro de Geografia e Estatística. (2017). Levantamento Sistemático da Produção Agrícola (LSPA): Pesquisa Mensal de Previsão e Acompanhamento das Safras Agrícolas no Ano Civil. Rio de Janeiro. 30(1), 1-81.

Juhász, A. C. P. (2003). Desafios fitossanitários para a produção de soja: Defesa vegetal e Sustentabilidade do agronegócio. Informe Agropecuário, Belo Horizonte, $34(1), 66-75$.

Keifer, H. H. (1965). Eriophyid studies. California, Bureal of Entomology.

Lindquist, E. E e Oldifield, C. N. (1996). Evolution and Phylogeny. Evolution of eriophyoid mites in relation to their host plant. p. 277-297. In E. E. Lindquist, M.W. Sabelis \& J. Bruin (eds.), Eriophyoid mites: their biology, natural enemies and control. Amsterdam, Elsevier, 790 p.

Lins, P. M. P. (2009). Avaliação agronômica de um sistema agroflorestal composto de progênies de cupuaçuzeiro e híbrido de coqueiro no município de Moju-Pa. Tese de Doutorado. $122 \mathrm{p}$.

Mariau, D. (1997). Aceria (Eriophyes) guerreronis: Un Important ravageur des Cocoteraies Africaines et Américaines. Oléagineux, 32(101-111). 
Research, Society and Development, v. 10, n. 17, e73101724282, 2021

(CC BY 4.0) | ISSN 2525-3409 | DOI: http://dx.doi.org/10.33448/rsd-v10i17.24282

Medeiros, N. C. G. de., Alves, J. B., Sales, F. das C. V., Monteiro, M. M., Nery, J. G. F., Martins, K. B. da S., Sousa, S. M. da S., Costa, A. A. da., \& Morais, G. V. de. (2021). Avaliação da eficiência do plano de manejo para zona de amortecimento. Research, Society and Development, 10(14), e133101421775. https://doi.org/10.33448/rsd-v10i14.21775.

Moore, D. L.; Alexander, R. A \& Hall. (1989). The Coconut Mite, Eriophyes Guerreronis Keifer In St Lucia Yield Losses And Attempts To Control It With Acaricide, Polybutene E Hirsutella Fungus. Trop. Pest Manag. 35(83-89).

Paul, A \& Mathew, T. B. (2002). Loss of husk, Quality of Fibre and Coir Due To the Infestation of Coconut Eriophyid Mite (Aceria guerreronis Keifer). Crops, $30(58-60)$.

Rodrigues, M. J. A.; Tavares, A. A.; Araújo, C. R.; Magalhães, J. A.; Teodoro, M. S \& Costa, N. L. (2016). Fauna edáfica em pastagens de Brachiaria Brizantha CV. Marandu em sistema Silvipastoril com coqueiros: Cadernos de Agroecologia. Universidade Federal do Piauí, 11(2).

Raupp, F. M., \& Beuren, I. M. (2006). Metodologia da pesquisa aplicável às Ciências Sociais. In I. M. Beuren (Ed.), Como Elaborar Trabalhos Monográficos em Contabilidade: Teoria e Prática (3rd ed., pp. 76-97). São Paulo: Atlas. 